\title{
KRT15 overexpression predicts poor prognosis in colorectal cancer
}

\author{
X. RAO, J. WANG, H. M. SONG, B. DENG, J. G. LI* \\ Department of Intensive Care Unit, Zhongnan Hospital, Wuhan University, Wuhan, China \\ *Correspondence: bladed12@sina.com
}

Received May 31, 2019 / Accepted July 23, 2019

\begin{abstract}
Keratin-15 (KRT15) is a type I keratin lacking a defined type II partner and plays a key role in maintaining cytoplasmic stability. Recently, studies have reported that KRT15 was correlated with tumor formation and progression. However, the clinical significance of KRT15 in colorectal cancer is unclear. In this study, we aimed to investigate the expression of KRT15 and its clinical significance in colorectal cancer. KRT15 expression was examined in 98 cases of colorectal cancer and matched adjacent normal tissues by quantificational real-time polymerase chain reaction (qRT-PCR) and immunohistochemistry (IHC), respectively. Then, the clinical significance of KRT15 expression was evaluated in colorectal cancer. QRT-PCR results revealed that the mRNA levels of KRT15 in colorectal cancer tissues were significantly higher compared with those in normal tissues $(\mathrm{p}<0.0001)$. The rates of KRT15 high-expression in colorectal cancer and normal tissues were $57.1 \%$ and $8.9 \%$, respectively, and the difference was statistically significant $(\mathrm{p}<0.0001)$. KRT15 high-expression correlated with differentiation, $\mathrm{T}$ stage, lymph node metastasis and clinical stage in colorectal cancer $(\mathrm{p}<0.05)$. Meanwhile, KRT15 overexpression predicted poor prognosis and could be used as an independent prognostic factor. These data indicate KRT15 is highly expressed in colorectal cancer and may serve as a prognostic biomarker.
\end{abstract}

Key words: KRT15, colorectal cancer, immunohistochemistry, biomarker, prognosis

Colorectal cancer (CRC) is the third most common cancer type in the world [1-2]. The incidence of CRC is predominated in 40-50 age group; however, an increasing burden of colorectal cancer is observed among younger adults [3-4]. Nowadays, surgery, chemotherapy and radiotherapy are main strategies for the treatment of CRC, however, the 5-year survival rate is less than $10 \%$ in metastatic cases [5-7]. Therefore, identifying the novel cancer-related genes is meaningful for the evaluation of clinical therapy.

Keratin-15 (KRT15) is a type I keratin lacking a defined type II partner, which plays a key role in maintaining cytoplasmic stability [8-10]. KRT15 is mainly expressed in basal keratinocytes of stratified epithelium, while abnormal expression of KRT15 is involved in tumor formation and progression [11-16]. However, the clinical significance of KRT15 in colorectal cancer is unknown.

In present study, KRT15 expression was detected in 98 cases of colorectal cancer and matched adjacent normal tissues. Moreover, the correlation between KRT15 expression and clinicopathological characters was further analyzed in CRC.

\section{Patients and methods}

Patient samples. A total of 98 paraffin-embedded tissue specimens from patients with colorectal cancer were obtained from March 2012 to August 2018 at the Zhongnan Hospital, Wuhan University. Matched adjacent normal tissues were more than $5 \mathrm{~cm}$ away from a tumor. Patients who received chemotherapy or radiotherapy before surgery were excluded from the study. Detailed patients ' information was obtained from medical records, including age, sex, tumor size, tumor differentiation, $\mathrm{T}$ stage, lymph node metastasis, distant metastasis and clinical stage. Follow-up time started from the day of surgery. Pathological diagnosis was confirmed by the pathologists in Zhongnan Hospital, Wuhan University. This study was performed in accordance with the Declaration of Helsinki and approved by the ethics committee of Zhongnan Hospital, Wuhan University. All patients signed an informed consent to agree with the use of samples.

qRT-PCR. All fresh tissues were collected after surgery and immediately stored in liquid nitrogen until RNA extraction. All operations were performed according to manufac- 
turer's instructions. Total RNAs were extracted using TRIzol reagent (Invitrogen, Grand Island, NY, USA) and reversetranscribed into cDNAs by using PrimeScript RT Reagent kit (TaKaRa Corp, Dalian, China). Then, DNAs/DNAs were amplified and quantified by TaqMan Universal PCR Master Mix (Applied Biosystems). Cycling conditions were $95^{\circ} \mathrm{C}$ for $3 \mathrm{~min}, 40$ cycles of $95^{\circ} \mathrm{C}$ for $10 \mathrm{~s}$ and annealing temperature for $10 \mathrm{~s}$. Fold changes were evaluated by delta-delta Ct method. The primer sequences of KRT15 were 5'AGAAATCTGAATTCCTATTGCAGGAGA-3' and 5'-CCCTGAAAGCTTAGACCGAGGGACCCT-3'. The primer sequences of GAPDH were 5'-GGAGCGAGATCCCTCCAAAAT-3' and 5'-GGCTGTTGTCATACTTCTCATGG-3'.

Immunohistochemical staining. Tissue sections were deparaffinized, rehydrated and immersed in hydrogen peroxide for blocking endogenous peroxidase activity. Antigen retrieval was performed by sodium citrate buffer ( $\mathrm{pH}$ 6.0). Then, sections were incubated with rabbit polyclonal
KRT15 antibody (Abcam Corp, USA, diluted 1:300) at room temperature for $2 \mathrm{~h}$. Then, sections were washed with PBS and incubated with biotin-labeled secondary antibodies at room temperature for $30 \mathrm{~min}$. Finally, sections were developed by diaminobenzidine tetrahydrochloride (DAB) and counterstained with hematoxylin staining (Zhongshan corp, China). Serum substituted the primary antibody was used as negative control. Based on the staining intensity and percentage of positive cells, immunohistochemical staining was analyzed independently by two pathologists. Staining intensity was recorded as 0 (negative), 1 (positive $1+$ ), 2 (positive $2+$ ) and 3 (positive $3+$ ). Percentage of cells were recorded as 1 (1-25\%), 2 (26-50\%), $3(51-75 \%)$ and 4 (76-100\%). Total score was calculated by multiplying the scores of staining intensity and percentage (range from 0 to 12). According to the receiver operating characteristic curve (ROC) analysis, KRT15 expression was divided into highexpression and low-expression.
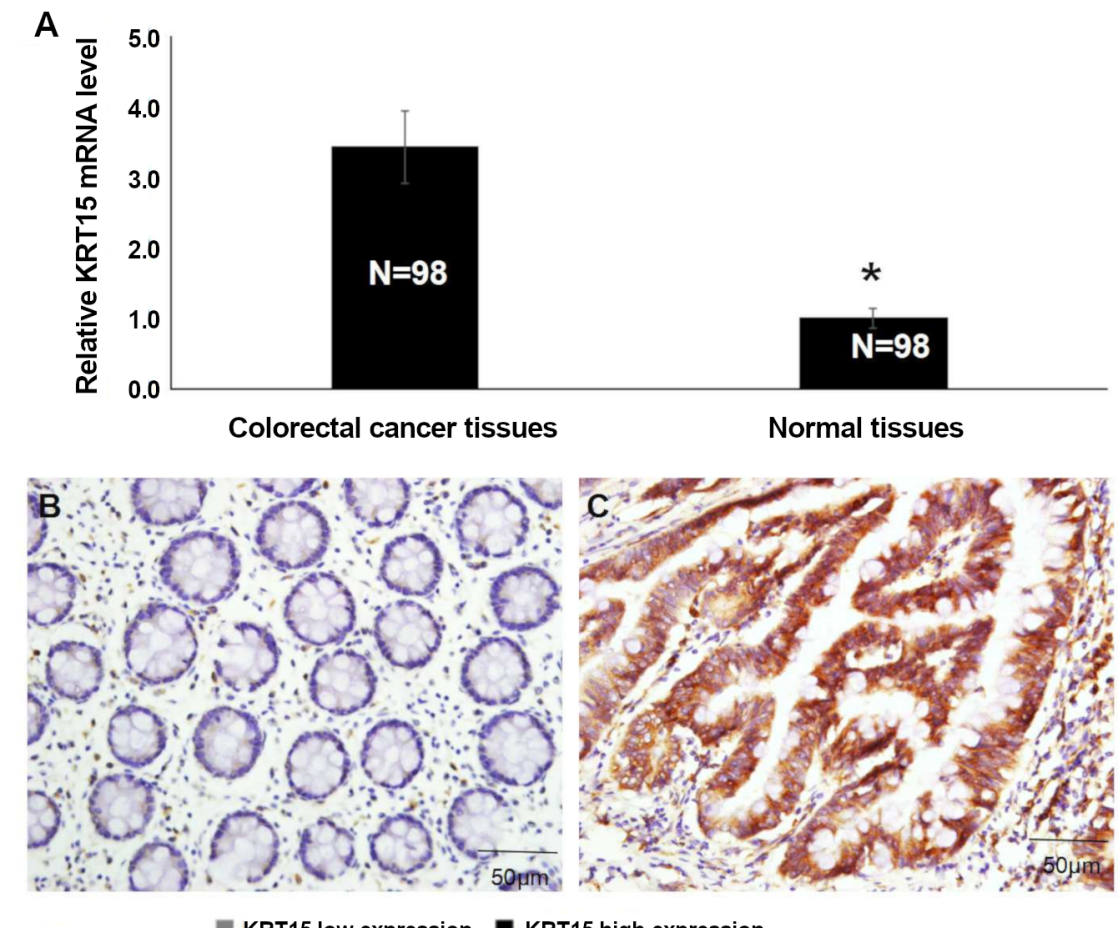

D

KRT15 low-expression

RT15 high-expression

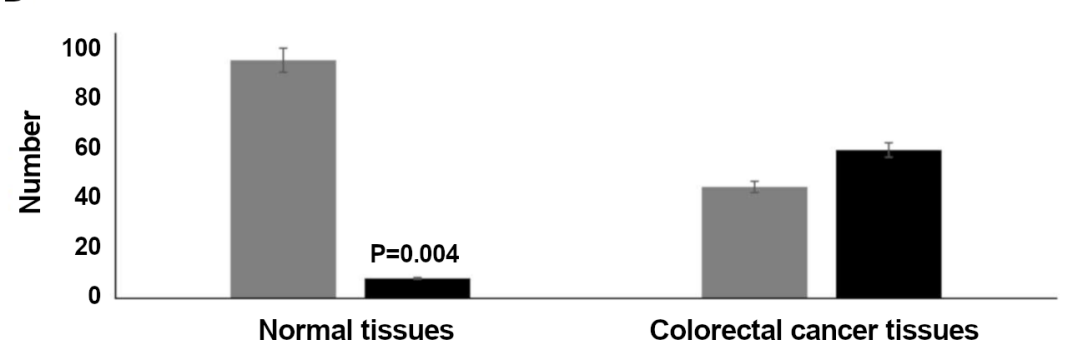

Figure 1. KRT15 expression was examined in colorectal cancer. A) The mRNA levels of KRT15 in colorectal cancer and normal tissues were measured by qRT-PCR (N=98). B) KRT15 low-expression was shown in normal tissues by IHC (N=98). C) KRT15 high-expression was shown in colorectal cancer tissues by IHC (N=98). D) A statistics graph for KRT15 expression in normal tissues and colorectal cancer tissues. *: Compared with colorectal cancer, $\mathrm{p}<0.0001$. 
Statistical analysis. All data were presented as mean \pm SD and analyzed by SPSS software (version 19.0; SPSS, Chicago, IL, USA). Paired t-test was used to analyze the mRNA levels of KRT15 between colorectal cancer and matched adjacent normal tissues. The correlation between KRT15 expression and clinicopathological characteristics was analyzed by Chi-square test $\left(\chi^{2}\right)$. Kaplan-Meier method and Cox's proportional hazards model were used to evaluate patients' survival. A $p<0.05$ was considered statistically significant.

\section{Results}

KRT15 is highly expressed in colorectal cancer. Firstly, the expression levels of KRT15 in colorectal cancer and matched adjacent normal tissues were detected by qRT-PCR. Results shown that the mRNA levels of KRT15 in colorectal cancer were significantly increased compared with those

Table 1. KRT15 expression was detected in colorectal cancer by IHC.

\begin{tabular}{|c|c|c|c|c|}
\hline \multirow[b]{2}{*}{ Types } & \multirow[b]{2}{*}{$\mathbf{N}$} & \multicolumn{2}{|c|}{ KRT15 } & \multirow[b]{2}{*}{ p-value } \\
\hline & & $\begin{array}{c}\text { Low-expression } \\
(\%)\end{array}$ & $\begin{array}{c}\text { High-expression } \\
\text { (\%) }\end{array}$ & \\
\hline Colorectal cancer tissues & 98 & $42(42.9)$ & $56(57.1)$ & 0.004 \\
\hline Normal tissues & 98 & $90(91.1)$ & $8(8.9)$ & \\
\hline
\end{tabular}

Table 2. The correlation between KRT15 expression and clinicopathological characters was analyzed in colorectal cancer.

\begin{tabular}{|c|c|c|c|c|}
\hline \multirow{2}{*}{$\begin{array}{l}\text { Clinicopathological } \\
\text { characters }\end{array}$} & \multirow{2}{*}{$\mathbf{N}$} & \multicolumn{2}{|c|}{ KRT15 } & \multirow{2}{*}{ p-value } \\
\hline & & \multicolumn{2}{|c|}{ Low-expression High-expression } & \\
\hline \multicolumn{5}{|l|}{ Age (years) } \\
\hline$\leq 54$ & 53 & 21 & 32 & 0.542 \\
\hline$>54$ & 45 & 21 & 24 & \\
\hline \multicolumn{5}{|l|}{ Gender } \\
\hline Male & 64 & 29 & 35 & 0.528 \\
\hline Female & 34 & 13 & 21 & \\
\hline \multicolumn{5}{|l|}{ Tumor size $(\mathrm{cm})$} \\
\hline$\leq 3$ & 39 & 21 & 19 & 0.103 \\
\hline$>3$ & 59 & 21 & 38 & \\
\hline \multicolumn{5}{|l|}{ Differentiation } \\
\hline High grade & 56 & 34 & 22 & $<0.0001$ \\
\hline Middle-low grade & 42 & 8 & 34 & \\
\hline \multicolumn{5}{|l|}{ T stage } \\
\hline $\mathrm{T} 1-\mathrm{T} 2$ & 68 & 36 & 32 & 0.004 \\
\hline $\mathrm{T} 3-\mathrm{T} 4$ & 30 & 6 & 24 & \\
\hline \multicolumn{5}{|c|}{ Lymph node metastasis } \\
\hline Negative & 62 & 34 & 28 & 0.003 \\
\hline Positive & 36 & 8 & 28 & \\
\hline \multicolumn{5}{|l|}{ Distant metastasis } \\
\hline Negative & 91 & 41 & 50 & 0.233 \\
\hline Positive & 7 & 1 & 6 & \\
\hline \multicolumn{5}{|l|}{ Clinical stage } \\
\hline I-II & 62 & 34 & 28 & 0.003 \\
\hline III & 36 & 8 & 28 & \\
\hline
\end{tabular}

in normal tissues $(\mathrm{p}<0.0001$, Figure $1 \mathrm{~A})$. Then, the protein expression levels of KRT15 in colorectal cancer and matched adjacent normal tissues were further examined by IHC. As shown in Figure 1B, positive staining of KRT15 was hard to detect in normal tissues, while it was easy to observe in colorectal cancer tissues (Figure 1C). According to the ROC analysis, IHC score $=6$ was regarded as the cut-off to differentiate KRT15 high-expression and low-expression. The rate of KRT15 high-expression in colorectal cancer was $57.1 \%$, which was significantly higher than those in normal tissues (8.9\%, Table 1, Figure 1D, p=0.004). Subsequently, the correlation between KRT15 expression and clinicopathological characteristics was analyzed in colorectal cancer. KRT15 high-expression was significantly associated with tumor differentiation, $\mathrm{T}$ stage, lymph node metastasis and clinical stage (Table 2, $\mathrm{p}<0.05$ ), while was not correlated with age, gender, tumor size and distant metastasis (Table 2, $\mathrm{p}>0.05$ ).

KRT15 overexpression predicts poorer prognosis in colorectal cancer. To investigate the correlation between KRT15 expression and patients' survival, Kaplan-Meier method and Cox's proportional hazards were performed. Kaplan-Meier analysis revealed that KRT15 expression, differentiation, $\mathrm{T}$ stage, lymph node metastasis, distant metastasis and clinical stage correlated with patients' survival (Table 3, p 0.05 ). Patients with KRT15 high-expression presented shorter survival time compared with those with KRT15 low-expression (Figure 2, p $<0.001$ ). Furthermore, Cox regression analysis shown that KRT15 expression as well as lymph node metastasis and distant metastasis were independent prognostic factors in colorectal cancer (Table 4, $\mathrm{p}<0.05)$.

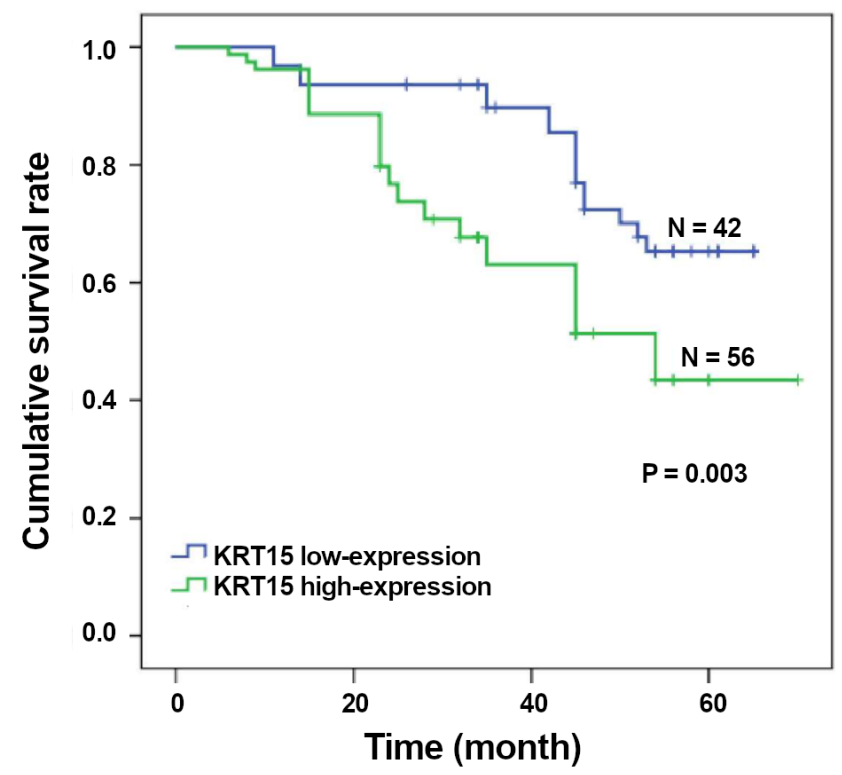

Figure 2. Kaplan-Meier survival analysis shown KRT15 overexpression predicted poorer prognosis in colorectal cancer. 


\section{Discussion}

KRT15, a type I keratin, is expressed primarily in the basal keratinocytes of stratified tissues [8]. Recent studies have reported that Keratin-15 expression is involved in tumor formation and progression [11-16]. KRT15 upregulation is

Table 3. Survival analysis was performed by Kaplan-Meier method.

\begin{tabular}{|c|c|c|c|}
\hline Variables & $\mathbf{N}$ & $\begin{array}{c}\text { Survival time } \\
\text { (Month, 95\% CI) }\end{array}$ & p-value \\
\hline \multicolumn{4}{|l|}{ KRT15 } \\
\hline Low-expression & 42 & $56(52-60)$ & 0.003 \\
\hline High-expression & 56 & $48(43-53)$ & \\
\hline \multicolumn{4}{|l|}{ Age (years) } \\
\hline$\leq 54$ & 53 & $52(46-58)$ & 0.648 \\
\hline$>54$ & 45 & $51(47-55)$ & \\
\hline \multicolumn{4}{|l|}{ Gender } \\
\hline Male & 64 & $52(47-57)$ & 0.276 \\
\hline Female & 34 & $53(48-58)$ & \\
\hline \multicolumn{4}{|l|}{ Tumor size (cm) } \\
\hline$\leq 3$ & 39 & $57(52-62)$ & 0.083 \\
\hline$>3$ & 59 & $48(44-52)$ & \\
\hline \multicolumn{4}{|l|}{ Differentiation } \\
\hline High grade & 56 & $56(53-59)$ & $<0.0001$ \\
\hline Middle-low grade & 42 & $43(37-49)$ & \\
\hline \multicolumn{4}{|l|}{ T stage } \\
\hline $\mathrm{T} 1-\mathrm{T} 2$ & 68 & $58(54-62)$ & $<0.0001$ \\
\hline T3-T4 & 30 & $39(32-46)$ & \\
\hline \multicolumn{4}{|c|}{ Lymph node metastasis } \\
\hline Negative & 62 & $55(52-58)$ & $<0.0001$ \\
\hline Positive & 36 & $42(35-49)$ & \\
\hline \multicolumn{4}{|l|}{ Distant metastasis } \\
\hline Negative & 91 & $56(53-59)$ & $<0.0001$ \\
\hline Positive & 7 & $12(10-14)$ & \\
\hline \multicolumn{4}{|l|}{ Clinical stage } \\
\hline I-II & 62 & $55(52-58)$ & $<0.0001$ \\
\hline III & 36 & $42(35-49)$ & \\
\hline
\end{tabular}

Table 4. Survival analysis was performed by multivariate Cox regression analysis.

\begin{tabular}{|c|c|c|c|}
\hline Variables & $\begin{array}{l}\text { Hazard } \\
\text { ratio }\end{array}$ & $95 \% \mathrm{CI}$ & p-value \\
\hline $\begin{array}{l}\text { KRT15 } \\
\text { (High-expression vs. Low-expression) }\end{array}$ & 2.319 & $1.268-4.242$ & 0.006 \\
\hline Age ( $\leq 54$ years vs. $>54$ years) & 1.121 & $0.546-2.300$ & 0.755 \\
\hline Gender (Female vs. Male) & 0.662 & $0.320-1.372$ & 0.267 \\
\hline Tumor size $(>3 \mathrm{~cm} \mathrm{VS} \leq 3 \mathrm{~cm})$ & 1.398 & $0.764-2.558$ & 0.277 \\
\hline $\begin{array}{l}\text { Differentiation } \\
\text { (Middle-low grad vs. High grade) }\end{array}$ & 2.284 & $0.669-7.796$ & 0.187 \\
\hline T stage (T1-T2 vs. T3-T4) & 1.645 & $0.491-5.513$ & 0.420 \\
\hline $\begin{array}{l}\text { Lymph node metastasis } \\
\text { (Positive vs. Negative) }\end{array}$ & 1.903 & $1.015-3.565$ & 0.045 \\
\hline $\begin{array}{l}\text { Distant metastasis } \\
\text { (Positive vs. Negative) }\end{array}$ & 36.598 & $10.534-127.145$ & $<0.0001$ \\
\hline Clinical stage (III-IV vs. I-II) & 0.856 & $0.171-4.363$ & 0.86 \\
\hline
\end{tabular}

observed in breast cancer [17], non-small cell lung cancer [18], urothelial cell carcinomas [19], ameloblastoma [20] and hepatocellular carcinoma [21]. KRT15 downregulation was found in oral squamous neoplasms [12], prostate tumors [22] and gastric cancer [23]. However, the expression of KRT15 in colorectal cancer remains unknown.

In this study, we detected the expression of KRT15 in colorectal cancer by qRT-PCR and IHC. Results showed that the mRNA levels of KRT15 in colorectal cancer were significantly increased compared with those in matched normal tissues. IHC results showed that positive staining of KRT15 was easily detected in colorectal cancer, while was hard to detect in normal tissues. Moreover, the rate of KRT15 highexpression in colorectal cancer was significantly greater than those in normal controls. These data indicated that KRT15 might be as an oncogene that implicated in the formation of colorectal cancer, which was consistent with the current reports [17-21]. The detection of KRT15 might be helpful for the diagnose of colorectal cancer. Moreover, KRT15 high-expression was significantly associated with tumor differentiation, $\mathrm{T}$ stage, lymph node metastasis and clinical stage in CRC, suggesting that KRT15 high-expression might contribute to tumor progression. Survival analysis shown that KRT15 was an independent prognostic factors in colorectal cancer and patients with KRT15 high-expression had poorer prognosis. These data indicated that KRT15 might serve as a prognostic biomarker in colorectal cancer. Furthermore, KRT15 was reported to be associated with breast cancer progression and could be as an independent prognostic factor $[9,17]$. Zhang et al. reported that KRT15 was differentially expressed in gastric cancer and associated with prognosis [23]. KRT15 expression was reported to be associated with tumor type, stage and differentiation grade in non-small cell lung cancer $[13,18]$. Therefore, our data was in line with these studies $[9,17-21]$ and further supported that KRT15 was an oncogene.

In conclusion, these data indicate that KRT15 as an oncogene is highly expressed in colorectal cancer. KRT15 overexpression might be involved in the formation and progression of CRC. Moreover, KRT15 overexpression predicts poor prognosis in colorectal cancer, which may serve as a prognostic biomarker. Of course, further investigations are needed to validate our findings.

Acknowledgments: Thanks for all patients who supported this study.

\section{References}

[1] LI R, ZHU H, YANG D, XIA J, ZHENG Z. Long noncoding RNA lncBRM promotes proliferation and invasion of colorectal cancer by sponging miR-204-3p and upregulating TPT1. Biochem Biophys Res Commun 2019; 508: 12591263. https://doi.org/10.1016/j.bbrc.2018.12.053 
[2] MIAO Z, DENG X, SHUAI P, ZENG J. Upregulation of SOX18 in colorectal cancer cells promotes proliferation and correlates with colorectal cancer risk. Onco Targets Ther 2018; 11: 8481-8490. https://doi.org/10.2147/OTT.S178916

[3] KARUNANITHI S, LEVI L. High-fat diet and colorectal cancer: myths and facts. Future Oncol 2018; 14: 493-495. https://doi.org/10.2217/fon-2017-0578

[4] SANDLER RS. Editorial: colonoscopy and colorectal cancer mortality: strong beliefs or strong facts? Am J Gastroenterol 2010; 105: 1633-1635. https://doi.org/10.1038/ajg.2010.97

[5] HONG M, ZHANG Z, CHEN Q, LU Y, ZHANG J et al. IRF1 inhibits the proliferation and metastasis of colorectal cancer by suppressing the RAS-RAC1 pathway. Cancer Manag Res 2019; 11: 369-378. https://doi.org/10.2147/CMAR.S186236

[6] KIM H, JUNG HI, KWON SH, BAE SH, KIM HC et al. Preoperative neutrophil-lymphocyte ratio and CEA is associated with poor prognosis in patients with synchronous colorectal cancer liver metastasis. Ann Surg Treat Res 2019; 96: 191-200. https://doi.org/10.4174/astr.2019.96.4.191

[7] JIANG W, YANG W, YUAN L, LIU F. Upregulation of AKIP1 contributes to metastasis and progression and predicts poor prognosis of patients with colorectal cancer. Onco Targets Ther 2018; 11: 6795-6801. https://doi.org/10.2147/ OTT.S151952

[8] WASEEM A, DOGAN B, TIDMAN N, ALAM Y, PURKIS P et al. Keratin 15 expression in stratified epithelia: downregulation in activated keratinocytes. J Invest Dermatol 1999; 112: 362-369. https://doi.org/10.1046/j.1523-1747.1999.00535.x

[9] CHONG LY, CHEOK PY, TAN WJ, THIKE AA, ALLEN G et al. Keratin 15, transcobalamin I and homeobox gene HoxB13 expression in breast phyllodes tumors: novel markers in biological classification. Breast Cancer Res Treat 2012; 132: 143-151. https://doi.org/10.1007/s10549-011-1555-6

[10] MAHALINGAM M, SRIVASTAVA A, HOANG MP. Expression of stem-cell markers (cytokeratin 15 and nestin) in primary adnexal neoplasms-clues to etiopathogenesis. Am J Dermatopathol 2010; 32: 774-779. https://doi.org/10.1097/ DAD.0b013e3181dafd8c

[11] CIMINO D, FUSO L, SFILIGOI C, BIGLIA N, PONZONE $\mathrm{R}$ et al. Identification of new genes associated with breast cancer progression by gene expression analysis of predefined sets of neoplastic tissues. Int J Cancer 2008; 123: 1327-1338. https://doi.org/10.1002/ijc.23660

[12] KHANOM R, SAKAMOTO K, PAL SK, SHIMADA Y, MORITA $\mathrm{K}$ et al. Expression of basal cell keratin 15 and keratin 19 in oral squamous neoplasms represents diverse pathophysiologies. Histol Histopathol 2012; 27: 949-959. https://doi.org/10.14670/HH-27.949

[13] GOMEZ-MORALES M, CAMARA-PULIDO M, MIRANDA-LEON MT, SANCHEZ-PALENCIA A, BOYERO L et al. Differential immunohistochemical localization of desmosomal plaque-related proteins in non-small-cell lung cancer. Histopathology 2013; 63: 103-113. https://doi.org/10.1111/ his. 12126
[14] GELFAND R, VERNET D, BRUHN KW, SARKISSYAN S, HEBER D et al. Long-term exposure of MCF-7 breast cancer cells to ethanol stimulates oncogenic features. Int J Oncol 2017; 50: 49-65. https://doi.org/10.3892/ijo.2016.3800

[15] HATTA M, MIYAKE Y, UCHIDA K, YAMAZAKI J. Keratin 13 gene is epigenetically suppressed during transforming growth factor-beta1-induced epithelial-mesenchymal transition in a human keratinocyte cell line. Biochem Biophys Res Commun 2018; 496: 381-386. https://doi.org/10.1016/j. bbrc.2018.01.047

[16] LION M, BISIO A, TEBALDI T, DE SANCTIS V, MENENDEZ D et al. Interaction between p53 and estradiol pathways in transcriptional responses to chemotherapeutics. Cell Cycle 2013; 12: 1211-1224. https://doi.org/10.4161/ cc. 24309

[17] FOLGUEIRA MA, BRENTANI H, KATAYAMA ML, PATRAO DF, CARRARO DM et al. Gene expression profiling of clinical stages II and III breast cancer. Braz J Med Biol Res 2006; 39: 1101-1113. https://doi.org/10.1590/s0100879x2006000800013

[18] SANCHEZ-PALENCIA A, GOMEZ-MORALES M, GOMEZ-CAPILLA JA, PEDRAZA V, BOYERO L et al. Gene expression profiling reveals novel biomarkers in nonsmall cell lung cancer. Int J Cancer 2011; 129: 355-364. https://doi. org/10.1002/ijc.25704

[19] TAI G, RANJZAD P, MARRIAGE F, REHMAN S, DENLEY $\mathrm{H}$ et al. Cytokeratin 15 marks basal epithelia in developing ureters and is upregulated in a subset of urothelial cell carcinomas. PLoS One 2013; 8: e81167. https://doi.org/10.1371/ journal.pone.0081167

[20] PAL SK, SAKAMOTO K, ARAGAKI T, AKASHI T, YAMAGUCHI A. The expression profiles of acidic epithelial keratins in ameloblastoma. Oral Surg Oral Med Oral Pathol Oral Radiol 2013; 115: 523-531. https://doi.org/10.1016/j. oooo.2013.01.017

[21] ZEKRI AN, EL-SISI ER, ABDALLAH ZF, ISMAIL A, BARAKAT BARAKAT A. Gene expression profiling of circulating CD133(+) cells of hepatocellular carcinoma patients associated with HCV infection. J Egypt Natl Canc Inst 2017; 29: 19-24. https://doi.org/10.1016/j.jnci.2016.12.002

[22] SHAN M, XIA Q, YAN D, ZHU Y, ZHANG X et al. Molecular analyses of prostate tumors for diagnosis of malignancy on fine-needle aspiration biopsies. Oncotarget 2017; 8: 104761-104771. https://doi.org/10.18632/oncotarget.22289

[23] ZHANG C, LIANG Y, MA MH, WU KZ, DAI DQ. KRT15, INHBA, MATN3, and AGT are aberrantly methylated and differentially expressed in gastric cancer and associated with prognosis. Pathol Res Pract 2019; 215: 893-899. https://doi. org/10.1016/j.prp.2019.01.034 